\title{
Econometric Analysis of Macroeconomic to Age-Specific Mortality Rate in Malaysia: Evidence from Panel Data
}

\author{
Robiaatul Adawiah Edrus, ${ }^{1,2}$ Zailan Siri $\mathbb{D}^{1},{ }^{1}$ Mohd Azmi Haron, ${ }^{1}$ \\ Muhammad Aslam Mohd Safari $\mathbb{D}^{3},{ }^{3}$ and Mohammed K. A. Kaabar $\mathbb{D}^{1,4,5}$ \\ ${ }^{1}$ Institute of Mathematical Sciences, Faculty of Science, University of Malaya, 50603 Kuala Lumpur, Malaysia \\ ${ }^{2}$ School of Economics, Finance, and Banking, College of Business, Universiti Utara Malaysia, 06010 Sintok, Kedah, Malaysia \\ ${ }^{3}$ Department of Mathematics and Statistics, Faculty of Science, Universiti Putra Malaysia, 43400 Serdang, Selangor, Malaysia \\ ${ }^{4}$ Gofa Camp, Near Gofa Industrial College and German Adebabay, Nifas Silk-Lafto, 26649 Addis Ababa, Ethiopia \\ ${ }^{5}$ Jabalia Camp, United Nations Relief and Works Agency (UNRWA) Palestinian Refugee Camp, \\ Gaza Strip Jabalya, State of Palestine
}

Correspondence should be addressed to Zailan Siri; zailansiri@um.edu.my and Mohammed K. A. Kaabar; mohammed.kaabar@wsu.edu

Received 3 November 2021; Accepted 15 January 2022; Published 18 February 2022

Academic Editor: Miaochao Chen

Copyright $\odot 2022$ Robiaatul Adawiah Edrus et al. This is an open access article distributed under the Creative Commons Attribution License, which permits unrestricted use, distribution, and reproduction in any medium, provided the original work is properly cited.

Human mortality is unanticipated and unavoidable, particularly in light of the recent COVID-19 pandemic. Insurance companies, actuaries, financial institutions, demographers, and the government may suffer catastrophic losses as a result of imprecise mortality estimates. Understanding the factors that contribute to mortality at the population level can help the government improve its efforts to promote health and reduce health inequalities. Consequently, the present study utilizes an econometrics model to estimate Malaysia's mortality rate, with macroeconomic factors as explanatory variables. The present study employed the unemployment rate, pension liabilities, gross domestic product, education expenditure, and healthcare expenditure as explanatory variables. The empirical results imply that the fixed effects model is feasible when using panel data across specific age groups. Moreover, the fixed effects model is devoid of cross-sectional dependency, heteroscedasticity, and serial correlation. The findings reveal that the unemployment rate, gross domestic product, and education expenditure all have a significant influence on the mortality rate. However, pension liabilities and health expenditure have an insignificant relationship with the mortality rate. The fixed effects model is demonstrated to be a robust model that fits the Malaysian scenario with an R-squared of approximately $84.69 \%$. The present study is novel due to the fact that the model established between explanatory variables and the mortality rate shows a significant relationship, which can be helpful in forecasting the mortality at population level as a preparation for the post-COVID-19 mortality. The present study aims to contribute to the development of an effective support mechanism by rectifying Malaysia's socioeconomic inequalities in order to mitigate the COVID-19 increase in mortality rate. Therefore, the Malaysian government is strongly encouraged to examine its expenditure on education and gross domestic product in order to improve the mortality rate, particularly among the adult and older population.

\section{Introduction}

Human mortality is an unanticipated event that is unavoidable and uncontrollable, significantly affecting people and society. The mortality prediction is utilized by demographers, insurance providers, financial institutions, actuaries, policymakers, and the government to forecast future initiatives to tackle the mortality trends. Imprecise mortality forecast imposes severe repercussions for all stakeholders. For instance, insurance providers may suffer catastrophic damages as a result of overpriced premiums, resulting in low-income consumers being unable to cover themselves [1]. Furthermore, an inaccuracy in mortality forecasting would result in an underestimation of premiums and reserves for annuity and pension products, leaving annuity and pension providers at risk of financial distress [2]. On the other hand, mortality levels are commonly regarded as an indicator of a population's overall well-being, 
where significant changes in a relatively short period may lead to numerous challenges to demographers and actuaries [3]. As a consequence, all stakeholders should constantly be alert to the mortality trend since they might have significant short- and long-term implications. However, one of the primary concerns of the mortality issue is the current global health emergency triggered by the pandemic COVID-19. The pandemic COVID-19 is also known as severe acute respiratory syndrome coronavirus 2 (SARS-CoV-2) and is extremely infectious to human respiratory, hepatic, gastrointestinal, and neurological systems of humans [4].

The current pandemic COVID-19 outbreak has resulted in significant mortality changes in a short period. The pandemic outbreak has revealed that the mortality rate from COVID-19 is higher in countries with a higher number of older adults aged 65 years and up $[5,6]$. With the downtrend in mortality rates, the ageing population is predicted to surge prior to the pandemic outbreak. In Malaysia, for example, the population aged 60 years and over, which is referred an ageing population, is predicted to accumulate up to 13.6 percent in 2030 from 6.2 percent in 2000 [7]. In the aftermath of COVID-19, Šimpach and Pechrová [8] showed that the previous mortality forecast prior to the pandemic outbreak can be driven away not only by the disease but also by other psychological factors. After a pandemic, the elderly population becomes the primary significant concern, as they are the most affected as compared to different age groups. For example, Jamaluddin et al. [9] examined social security for Malaysia's ageing population. They concluded that the current social security framework is incapable of supporting the society, regardless of demography's age profile or economic circumstances. Furthermore, Chung et al. [10] highlighted the importance of developing effective programmes to support Malaysia's most vulnerable groups, particularly older adults, so that they can adapt to their new surroundings and participate effectively in social and economic activities. As a necessary consequence, the mortality forecast for the post-COVID-19 period must account for the excess mortality caused by the pandemic.

Excess mortality occurs when normal mortality differs from mortality during a pandemic. For example, the higher death rate caused by COVID-19 was discovered by the authors of Refs.[11-13]. Since mortality is an unprecedented event, a variety of mortality models have been developed to predict mortality throughout the years. One of the established mortality models, the Heligman-Pollard model, comprises eight parameters that predict varying mortality for each age $[14,15]$. Aside from that, the Lee-Carter model predicts the mortality rate by including the time parameter [16]. In accordance with the development of the mortality model, Booth and Tickle [17] reviewed and classified the most significant development in mortality forecasting since 1980. The present study estimates the mortality rate from the viewpoint of the econometric model rather than utilizing the mortality model in estimating the mortality rate. Since this model incorporates time-series data and uses macroeconomic indicators, the econometric model is essential for economists and academicians to forecast and plan for the future. Moreover, Hansen [18] highlighted that selecting an econometric model should be based on four criteria: (a) a semiparametric vision, (b) model should be viewed as an approximation, (c) model should be evaluated according to its goal, and (d) model uncertainty should be included into inference methods. Furthermore, the government may be able to enhance the economy through improving health by better understanding the factors that drive the mortality rate at the population level.

The present study adopts panel analysis to estimate the mortality rate using the macroeconomic indicators as explanatory variables. Based on the previous literature, the present study includes a few macroeconomic indicators. Studies carried out by Ruhm $[19,20]$ to study the effect of unemployment rates on mortality rates discovered that the state unemployment rates in the United States are negatively and significantly related to total mortality rates. By using panel data analysis, the author discovered that mortality is pro-cyclical since it is associated with the business cycle. Another study conducted in Germany to investigate the association between aggregate mortality and economic fluctuations for a separate nation state revealed that recessions lower aggregate mortality rates for overall age groups and individual age group mortality rates [21]. The association between mortality and unemployment has been justified in the earlier literature without taking into account other macroeconomics variables. Therefore, the present study includes another explanatory variable, such as pension liabilities, to estimate the mortality rate at the population level. The pension liabilities variable is included in the present study due to an increase in the retirement age in 2012. The improvement in the mortality rate has resulted in an increase in the retirement age. Therefore, the present study includes pension liabilities to investigate the influence of pension liabilities on the mortality rate at the population level.

On the other hand, Ibrahim et al. [22] examined the influence of actuarial assumptions on Malaysia's pension liabilities and concluded that mortality has a considerable influence on pension liabilities. The present study utilizes the expected present discounted value of pension annuities earned by retirees to determine the pension liabilities. The expected present discounted value is commonly related to the purchase price of an annuity in determining the money's worth ratio [23]. For instance, a study conducted by Poterba and Solomon [24] estimated the expected present discounted value of future payment streams and mortality rates in the United States and identified that the expected discounted value is sensitive to the mortality rate assumption. As a consequence, the present study uses the expected present discount value as a proxy for the pension liabilities. The next explanatory variable considered in the present study is the economic growth rate, which is generally estimated from the gross domestic product.

Despite the long-run strong negative association between gross domestic product and mortality, the short run between these two is still debated. Therefore, the present study investigates the influence of short-term economic growth on the mortality rate. The long-standing belief that economic growth is the leading factor in reducing mortality 
has been contemplated in a variety of countries, using a variety of approaches over a range of time frames [25]. This emphasizes the importance of continuing research into the connection between economic growth and mortality. Depending on the mortality population group and cause of death, the relationship between these two may be different. In China, for instance, economic growth affects adult mortality but not infant mortality [26]. In addition, Kirigia et al. [27] discovered that maternal mortality had a statistically negative effect on the gross domestic product in the World Health Organization (WHO) African region. Due to the flexible relationship between mortality and economic growth, the present study includes economic growth as one of the explanatory variables.

Furthermore, the present study is based on studies a study conducted by Eboh and Metiboba [28] that attempted to examine the effect of economic conditions on the aggregate mortality rate of a certain age group. Moreover, some of the explanatory variables included in the present study are based on the interest variable carried out by Kousar et al. [29]. From the previous literature, the present study adopts panel data to analyse macroeconomic conditions such as unemployment rate, pension liabilities, gross domestic product, education expenditure, and healthcare expenditure in estimating the mortality rate. Due to its flexibility in capturing both fluctuations across time and individual effects, panel data analysis has become a prominent instrument in economics and finance research [30].

The main motivation for pursuing this research, taking Malaysia as a case study, is to take advantage of Malaysia's peculiarity in having a multiracial population to boost the economy in various industries. Besides that, Malaysia is also one of Southeast Asia's fastest developing countries, having been hit by a series of economic crises, including the 1985-1986 Oil Price Crisis, 1997-1998 Financial Crises, and 2009 World Economic Subprime Crisis [31]. Furthermore, Malaysia's recent COVID-19 pandemic outbreak had a severe influence not only on economic growth but also in terms of the maritime sector, demographics, psychology, education, and tourism [32-35]. As of September 20, 2021, Malaysia recorded the highest cumulative mortality rate among the Southeast Asian countries [36]. As a consequence, the present study estimates the factor contributing to mortality rate at the population level by employing unemployment rate, pension liabilities, gross domestic product, education expenditure, and healthcare expenditure on mortality rates.

According to the best of our knowledge, the results in the present study provide a good contribution by forecasting the mortality rate at the population level rather than using the mortality models. Therefore, all the results in the present study are considered new and original in this investigated field of research. The present study is being carried out as a preparation to estimate the mortality rate for post-COVID19 in order to mitigate the effects of a higher mortality rate. In addition, the present study contributes to the ongoing literature by examining the effects of the unemployment rate, pension liabilities, macroeconomic conditions, education expenditure, and healthcare expenditure on the mortality rate. This paper is organized as follows: In Section 2 , a review of literature is presented with a description of hypothesis development. In Section 3, theoretical framework is discussed. The methodology of our study is introduced in Section 4. The presentation of main results is provided in Section 5. The key findings and discussion of our work are included in Section 6. A conclusion of our study is presented in Section 7.

\section{Review of the Literature and Hypothesis Development}

2.1. Ageing Population, Retirement, and Economic Growth. An ageing population and aged population are formed when the population of senior citizens 60 years and older approaches 7 percent and 14 percent of the total population, respectively [37]. The population of Malaysia in 2020 is estimated to be at 32.7 million compared to 32.5 million in 2019 , with an annual growth rate of 0.4 percent [38]. In the year 2020, the number of senior adults aged 60 years and more is predicted to be around 10.7 percent, rising to approach 15.3 percent by 2030 [39]. Thus, Malaysia is currently experiencing an ageing population and is expected to form the aged population in the year 2030. Furthermore, Chung and Mansur [40] concluded that Malaysia is expected to have the most difficult time dealing with post-effect ageing as compared to Japan, Singapore, and South Korea. This group's increase indicates a considerable increase in life expectancy and death rates. In 1991, the government introduced the Employee Provident Fund (EPF) Act in order to ensure the well-being and social security of the elderly [41]. In addition, under the civil service pension scheme, the government has issued specified pension annuities to government retirees. Furthermore, the government has made a continual effort to prepare the senescence group for living after retirement by improving amenities and facilities, providing accessible health care, utilizing ICT to disseminate information on public services related to ageing, and implementing a variety of other programmes [42].

The essential issue after retirement for the working population is maintaining their standard of life, regardless of their health or age. However, [43] highlighted that approximately 30 percent of the older population group, representing 6 percent of the overall population, is considered officially living below Malaysia's poverty level. Nevertheless, pensioners from the public sector obtain pension annuities from the time they retire until they die, which they can use to spend during their retirement [44]. On the other hand, private sector retirees would not receive any pension annuities during retirement; instead, they will receive a one-time pay out as their retirement fund under the EPF scheme. In Malaysia, there are three multipillar retirement systems: (i) a defined benefit plan known as the pension scheme, which was available to permanent civil personnel; (ii) a defined benefit plan, which is mandatory for private-sector workers and those who opt to contribute to the EPF; and (iii) an optional scheme [45]. Basically, three types of payments are available to civil employees when they retire: gratuity, Cash Award in Lieu of Accumulated Leave 
(GCR), and pension annuities. The gratuity and GCR are one-time payments, whereas pension annuities are paid as long as the person is alive during their retirement term. Improvement of mortality rate is associated with longer life expectancies, resulting in a larger annuity budget that the government should indeed spend to support pension liabilities. Moreover, the current pension scheme will not be fiscally sustainable due to the ageing population, rising life expectancy, and ballooning pension payments [46].

According to the Melbourne Mercer Global Index 2019, Malaysia's pension system scored 60.6 percent for the overall performance with 50.5 percent, 60.5 percent, and 76.9 percent for adequacy, sustainability, and integrity, respectively [47]. As a result, the retirement system's adequacy and sustainability have become a huge challenge in Malaysia. Although the number of civil servants in Malaysia is estimated to be around 1.6 million [48], the pension scheme's financial sustainability becomes a fiscal burden. In a nutshell, as the number of older retirees rises and retirees live longer, the pension scheme may not be sustainable in the long run [49]. As a possible consequence, the Malaysian Labour Law stipulates the compulsory retirement age at 60 years. As a natural outcome, the issue that evolves upon retirement is the inadequate funding offered by the government or private institutions/companies for retirees to encounter their retirement period from the age of retirement till death [50]. A study conducted by Asher and Bali [45] reported that Malaysia's civil service pension scheme has a ratio of less than half of the present working-age population covered by social security. It reflects that the proportion of persons employed in the civil service is less than half of the total number of people employed. Consequently, the macroeconomic situation will be influenced as the existing working population continues to diminish, as taxpayers with incomes lower than the population must be covered by social security.

Since the retirement age has been raised to 60 years old, the concern about the unemployment rate, particularly among adults aged 30 years and below, while people are leaving the workforce later, job opportunities should be widened to satisfy pension liabilities and unemployment issues at the same time. In developed countries, RozenBakher [51] highlighted that raising the retirement age has an influence on the labour force market, which is already suffering from a lack of accessible jobs, resulting in a rise in young and adult unemployment but a decrease in senior unemployment. Figure 1 shows the unemployment rate based on age groups from 2001 to 2019 in Malaysia. From 2001 through 2019, the overall unemployment rate fluctuated between 2.5 and 4.0 percent. Figure 1 illustrates that the unemployment rate for the age group 25-29 has been rising since 2013 and has already surpassed the total unemployment rate. This trend shows that the youth group suffers from unemployment issues after the implementation of the maximum retirement age of 60 years old in the year 2012. It can be seen that the youth have been affected by a lack of job opportunities, as their unemployment rate has been rising. Furthermore, Malaysia's pensioner-to-worker ratio was 1: 12 in 2010 but is predicted to drop to $1: 5$ by 2040 [52]. It implies that the working group will gradually decline, emphasizing that the government should pay particular attention to this issue.

After four quarters of recession, Malaysia's gross economic product rose 16.1 percent in the second quarter of 2021; however, it is still below the pre-COVID-19 level of the fourth quarter of 2019 [39]. Economic inequalities should be addressed as they are recognized to be key drivers of other dimensions of inequalities, such as health inequalities. Apparently, the percentage of healthcare expenditure as a percentage of total gross domestic products fluctuated about three percent in Malaysia [53]. The educational growth of a nation is boosted by increased government expenditure on education, which results in sociological transformation. Furthermore, the education and health sectors play vital roles in escalating labour force productivity and contributing to national output [29]. Government expenditure on education and health aids in boosting the population's access to these services. In addition, better education and health facilities contribute to economic development.

\subsection{Association between Unemployment and Mortality.} For decades, the correlation between unemployment and mortality has been a contentious topic in health unemployment research. The relationship between these two frequently encounters a different correlation, either positive, negative, or inconsequential correlations [54]. Although these two have a flexible relationship, the relationship between unemployment and mortality varies depending on circumstances, whether short term or long term [55]. An analysis of the relationship between unemployment and mortality found that the risk of cumulative mortality is nearly three times higher among unemployed men than among employed men. Still, there is no significant relationship among unemployed women [56]. In addition, Jin et al. [57] identified a significant association between national unemployment levels and overall mortality rates. They found strong evidence to indicate a linkage between unemployment and a higher risk of mortality at the population level. Furthermore, Granados [58] found a negative and statistically significant relationship between province unemployment and total death rates. On the other hand, Martikainen [59] discovered a causal relationship between unemployment and male mortality. However, in the United States, there is additional evidence of a negative correlation between unemployment and mortality [60]. Meanwhile, in the early 2000s, a link was discovered between unemployment and mortality in South Korea [61]. Furthermore, mortality was found to be greater among those who were unemployed in Finland [62]. Based on the previous literature, the present study hypothesized the following relationship between unemployment and mortality:

$H_{1}$ : there is a significant relationship between unemployment and mortality.

2.3. Association between Pension Liabilities and Mortality. Pension liabilities have risen as the mortality rate has improved and life expectancies have increased, resulting in an ageing 


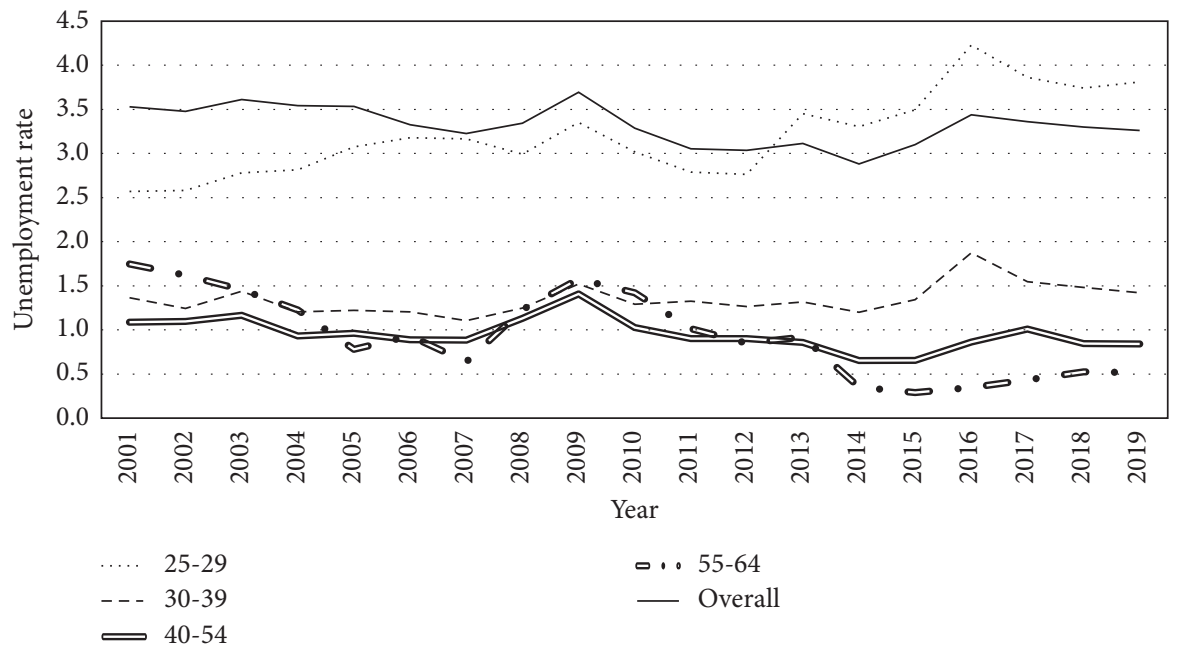

FIgURE 1: Unemployment rate (\%) based on age group in Malaysia. Source: authors' computation from the Rating Agency Malaysia (2020) data.

population. As a possible outcome, the government of Malaysia must cover the pension liabilities for the public civil pension scheme from the time a person retires until death. In addition, if the retirees have dependents who are eligible for pension derivatives, the dependents will receive pension annuities. A study performed by Ibrahim and Siri [63] explained the pension derivatives and estimated the longevity factor, demonstrating that pension liabilities increase substantially as the ageing population grows. The mentioned authors demonstrated that with the increment of the ageing population, the government has to bear the pension liabilities, particularly for public pensioners. In addition, Jaafar et al. [52] advocated that the current pension system is critical in guaranteeing those future retirees and the senescence population to maintain their standard of living towards the end of their working lives.

Moreover, Darmaraj and Narayanan [46] proposed that the retirement age should be raised to 65 years old to minimize the pension deficit as the mortality rate decreases the result of an increase in life expectancy. The mortality is an unforeseeable event that significantly influences pension liabilities, raising the retirement age will result in a shorter retirement year, implying a reduction in pension liabilities [64]. By evaluating the longevity factor, Ibrahim [65] recommended reforming the existing retirement system in order to reduce pension liabilities, which considers the surviving period after retirement. In a nutshell, the sustainability of the pension scheme can be secured by minimizing the pension liabilities. As shown by the previous literature, increasing the retirement age is a feasible alternative for ensuring the pension scheme's long-term viability. Consequently, an increase in retirement age leads to an increase in unemployment for a specific age group, particularly for young people who enter labour between the ages of 25 and 29 . The present study hypothesized the following association between pension liabilities and mortality based on the previous literature:

$\mathrm{H}_{2}$ : there is a significant positive relationship between pension liabilities and mortality.
2.4. Association between Gross Domestic Product and Mortality. The relationship between mortality and economic growth appears to be debatable depending on the range of time, country, or even gender. For instance, Gerdtham and Johannesson [66] investigated the impacts of the business cycle on mortality risk and discovered a substantial countercyclical relationship between the GDP change and the mortality risk solely for men. Another study that examined the influence of maternal mortality on the GDP discovered a statistically significant negative relationship between these two [27]. The present study proposed the following hypothesis between gross domestic product and mortality based on past literature:

$\mathrm{H}_{3}$ : there is a significant negative relationship between gross domestic product and mortality.

2.5. Association between Education Expenditure and Mortality. Systematic analyses of mortality by socioeconomic status were apparently initiated by William Farr, whose life was devoted to the social applications of vital statistics [67]. The aforementioned authors highlighted the inverse relationship between education and total mortality in Washington, Maryland. Apart from that, economists are progressively disputing the mechanisms that explain the strong empirical correlation between education and health $[68,69]$. Rather than assessing the overall association between education and mortality, Leive and Ruhm [70] demonstrated that the association between those two can differ by gender. The mentioned authors found that the least-educated women had the highest mortality trends, but this is not true for men. The present study develops the following association between education expenditure and mortality based on existing literature:

$\mathrm{H}_{4}$ : there is a significant negative relationship between education expenditure and mortality.

2.6. Association between Healthcare Expenditure and Mortality. The government's increased healthcare expenditure has piqued the interest of academicians, 
policymakers, and the general public. For instance, there is a significant long-run inverse relationship between government healthcare expenditure and infant mortality rate and under-five in Namibia [71]. Furthermore, a meta-analysis regression conducted by Gallet and Doucouliagos [72] highlighted the inverse relationship established between healthcare expenditures and mortality in the previous literature, favouring healthcare expenditure reducing mortality. The present study develops the following hypothesis of the relationship between healthcare expenditure and mortality:

$\mathrm{H}_{5}$ : there is a significant negative relationship between healthcare expenditure and mortality.

\section{Theoretical Framework}

The present study contributes to the ongoing research to determine the existing relationship between macroeconomic indicators and mortality rates from the existing literature. Therefore, the present study hypothesized that there is a relationship between the explanatory variable and the independent variable. When analysing panel data, cross-sectional data are frequently examined across different spaces such as countries. However, the present study applies cross section from several age groups as cross-sectional data. The government and policymakers can offer alternative strategies to address the mortality rate using different approaches based on age groups. Due to the wide availability of data, panel data analysis has become widely applicable in different researches, providing benefits to researchers, academics, policymakers, and the government. Before carrying out the analysis, the present study hypothesizes the following relationship between the explanatory variables and the dependent variable based on prior literature. The first explanatory variable, the unemployment rate, might have a positive or negative relationship with the mortality rate. The second explanatory variable, pension liabilities, is expected to have a proportional relationship with the mortality rate. Meanwhile, the mortality rate is expected to be inversely proportional to the other three explanatory variables: gross domestic product, education expenditure, and health expenditure:

$H_{1}$ : there is a significant relationship between unemployment and mortality.

$\mathrm{H}_{2}$ : there is a significant positive relationship between pension liabilities and mortality.

$\mathrm{H}_{3}$ : there is a significant negative relationship between economic growth and mortality.

$\mathrm{H}_{4}$ : there is a significant negative relationship between education expenditure and mortality.

$H_{5}$ : there is a significant negative relationship between healthcare expenditure and mortality.

\section{Methodology}

The most convenient method for examining the relationship between two or more variables over time is by using the linear of non-linear regression to regress the explanatory variable against the independent variable. However, Søgaard [73] concluded that time-series regression analysis is an inadequate methodology and should be avoided in epidemiology and social science research. As a consequence, the present study employs panel analysis, which combines timeseries and cross-sectional data. Previous research has applied panel data and included the same variables as the present study [74-76].

4.1. Data and Variables. The present study uses panel data, which combines cross-sectional (age group) and time-series data. The age range for cross-sectional data is 25 to 64 years old, with four age groups: (a) 25-29 years old, (b) 30-39 years old, (c) 40-54 years old, and (d) 55-64 years old. These groupings are categorized based on the author's justification according to the working-age group. The first group denotes the beginning of working life, the second group represents early working life, the third age group describes a stable working period, and the last age group indicates senior working age. The overall data cover the years 2008 through 2018. The present study focuses on the year in which the retirement age was raised, which was in 2012.

The present study investigates the effect of macroeconomic conditions such as unemployment rate, pension liabilities, gross domestic product, education expenditure, and healthcare expenditure on mortality rate. The mortality rate is the dependent variable, while the unemployment rate, pension liabilities, gross domestic product, education expenditure, and healthcare expenditure are the explanatory variables. The mortality rate, unemployment rate, and pension liabilities are all separated by the age group. Due to the lack of data for each group, the gross domestic product, education expenditure, and healthcare expenditure variables provide the same number for each age group.

4.1.1. Mortality Rate. The mortality rate is computed by dividing the number of deaths by the number of exposures. The number of exposures is yielded by averaging the number of populations at the beginning and end of a year. The number of deaths and the number of populations are extracted from the Department of Statistics, Malaysia.

4.1.2. Unemployment Rate. The unemployment rate is calculated using the number of employed and the total number of labour forces supplied by the Rating Agency of Malaysia (RAM). Labour force refers to those who are employed or unemployed during the reference week and are between the ages of 15 and 64 years old (in completed years at the last birthday). Unemployed refers to those who are unemployed but interested in working. The unemployment rate is the proportion of the unemployed people to the total number of people in the labour force, which measures the percentage of people who are unemployed. Although the labour force ranges from 15 to 64 years old, the present study restricts the age category to 25 to 64 years old in order to match the pension liabilities data. 
4.1.3. Pension Liabilities. The present study applies the expected present discounted value as a proxy to estimate the pension liabilities, which has been employed in the previous literature $[63,64]$. The pension annuities are extracted from the Post-Pension Division, Public Service Department, cooperating with the Retirement Fund (Incorporated). The data obtained are in the form of an individual account, which includes the date of retirement, type of retirement, length of services, age upon retirement, income before retirement, and amount of pension payment as of October 2020 (date of data extraction) from 2008 until October 2020. The present study computes the expected present discounted value from the number of pension payments by summing up the amount of pension received for the same age group for each year. The amount is then discounted to obtain the present value of the first pension amount received upon retirement. The present study uses the annuities with discounted value and risk-free interest rate acquired from the Central Bank of Malaysia, as well as the annual increase in pension annuities. The pension annuities have been increased by 2 percent every year to adjust with the inflation rate starting in 2013 [44].

4.1.4. Gross Domestic Product. Gross domestic product is the sum of gross value generated by all resident producers in the economy plus any product taxes, minus any subsidies not included in the value of the products. It is calculated in Ringgit Malaysia without taking into account the depreciation of fabricated assets or natural resource depletion and degradation [53]. The gross domestic product is measured using three approaches: the production approach, the expenditure approach, and the income approach. The present study considers gross domestic product as a reading indicator of economic growth.

4.1.5. Education Expenditure. Government expenditure is extracted from the gross domestic product, which is measured using the expenditure approach. This approach is used to measure the value of goods and services, often known as final demand or final expenditure. Government expenditure on education is expressed as a percentage of gross domestic product, which is computed from the total percentage of gross domestic product. The education expenditure is extracted from the World Bank.

4.1.6. Healthcare Expenditure. Total expenditure on health is the sum of aggregate public and private healthcare expenditure for a specific time throughout the year. The healthcare expenditure data are extracted from the Malaysia National Health Accounts, Health Expenditure Report. The Malaysia National Health Accounts report estimates macro national health expenditure estimations based on three dimensions: (i) sources of financing, (ii) providers of healthcare, and (iii) functions of the healthcare.

4.2. Model Specification. Based on the hypothesis's development, the present study investigates the effect of the unemployment rate, pension liabilities, economic growth, education expenditure, and healthcare expenditure on mortality rate using the model formulated in Equation (1). Overall, only two variables are recorded in percentage, which is the unemployment rate and government expenditure on education. The transformation into a logarithm is required for the remaining variables because they are recorded in their own unit:

$$
\begin{aligned}
\log \mathrm{MR}_{i t}= & \beta_{0}+\alpha_{1} \mathrm{UR}_{i t}+\alpha_{2} \log \mathrm{PL}_{i t}+\alpha_{3} \log \mathrm{GDP}_{i t} \\
& +\alpha_{4} \mathrm{EDU}_{i t}+\alpha_{5} \log \mathrm{HEXP}_{i t}+U_{i}+\varepsilon_{i t},
\end{aligned}
$$

where log: logarithm transformation, $\mathrm{MR}_{i t}$ : mortality rate for cross-section $i$ and time-series $t, \mathrm{UR}_{i t}$ : unemployment rate for cross-section $i$ and time-series $t, \mathrm{PL}_{i t}$ : pension liabilities for cross-section $i$ and time-series $t, \mathrm{GDP}_{i t}$ : gross domestic product for cross-section $i$ and time-series $t, \mathrm{EDU}_{i t}$ : education expenditure for cross-section $i$ and time-series $t, \mathrm{HEXP}_{i t}$ : healthcare expenditure for cross-section $i$ and time-series $t$, $\beta_{0}$ : model constant, $\alpha_{i}$ : coefficients for each explanatory variable, $j=1,2,3,4,5, U_{i}$ : unobserved effects across $i$, and $\varepsilon_{i t}$ : idiosyncratic error terms vary between $i$ and $t$.

4.2.1. Unit Root Test. The panel unit root test utilizes pooled cross-section time-series data. The null hypothesis is that each cross-section time series consists of a unit root against the alternative hypothesis that each time series is stationary [77]. The Levin-Lin-Chu test demonstrates that all variables are stationary.

4.2.2. Hypothesis Test. The hypothesis test is performed to identify the most feasible model that fits the data. First, an F-test is conducted to determine whether the ordinal least square model or the fixed effects model is more feasible. The fixed effects model is the preferable model based on the F-test. The Lagrange multiplier test [78] is then performed to detect the existence of age group (individual) or time unobserved effects. The outcome demonstrates that the random effects model is the best option. Finally, the Hausman test is conducted to identify whether a consistent or efficient model is the feasible model [79]. Through the Hausman test, the consistent model, represented by the fixed effects model, is the preferred model. The fixed effects model minimizes the risk of bias present in time-series or cross-sectional analysis due to the inability to adjust the effect for omitted variables that influence mortality and are correlated with economic conditions over time or across age group. By using the least square dummy variable (LSDV) for estimating the fixed effects model, three explanatory variables display a significant relationship with the mortality rate.

4.2.3. Diagnostic Test. A few tests are conducted to identify the most feasible model, which are cross-sectional independence [80], first-order serial correlation (Wooldridge test), and group-wise heteroscedasticity (modified Wald test). With all of the diagnostic checks, the fixed effects model displays no issues. 


\section{Results}

5.1. Descriptive Statistics. Table 1 reports the mean, minimum, maximum, and standard deviation values of all variables, including the independent variable and explanatory variables. Only the unemployment rate and education expenditure are expressed in the percentage, while all other variables are transformed into logarithms for easier results' interpretation. In addition, there are minimum, maximum, and standard deviation figures for overall data across age group and time series.

Only the mortality variable has a negative value when the measurement units are removed, whereas the remaining variables have a positive mean value. Therefore, according to the overall standard deviation, the GDP variable has the lowest value (0.0980467) and the pension liabilities' variable has the highest value (1.8352330), implying that their dispersion from the mean is the lowest and the largest, respectively. Furthermore, the fact that the gross domestic product, education expenditure, and healthcare expenditure variables reported the same values across age group and the standard deviation across age group indicates no dispersion because these variables are based on the same data for each age group.

Table 2 shows the robust model of the fixed effects model. The mortality rate is significantly associated with the unemployment rate, gross domestic product, and government expenditure on education. A one percent increase in the unemployment rate implies a 0.031 percent decrease in the mortality rate. Conversely, a one percent increase in pension liabilities leads to a 0.021 percent rise in the mortality rate. However, the pension liabilities variable shows an insignificant relationship with the mortality rate. Hence, with every one percent increase in gross domestic product, the mortality rate falls by 0.623 percent. In addition, a one percent increase in education expenditure results in a 0.191 percent reduction in mortality. Furthermore, for every one percent increase in healthcare expenditure, the mortality rate will increase by 0.419 percent. However, the relationship established between healthcare expenditure and mortality is not significant. Since there are no data by age group on GDP, education expenditure, and healthcare expenditure, which are available, the present study employs the same data for all age groups. The $\mathrm{R}$ squared for this robust model is around 84.69 percent, implying that the mortality rate could be explained as much as 84.69 percent by the unemployment rate, pension liabilities, gross domestic product, education expenditure, and healthcare expenditure. In a nutshell, it implies that this model is robust and fits well with the Malaysia scenario.

\section{Findings and Discussion}

According to the findings of the present study, as the unemployment rate rises by one percent, the mortality rate is estimated to fall by 0.031 percent over time. It means that between 2008 and 2018, Malaysia's unemployment rate and death rate have had a significant negative relationship. In Spain, there is also a significant negative relationship between unemployment and mortality. Furthermore, a study conducted by Granados [58] found that an increase of 5 percentage points in the unemployment rate will result in a 0.55 percent drop in mortality. Moreover, Ruhm [20] estimated the effect of health status and medical care utilization on unemployment and discovered a negative relationship, implying that a one percent decrease in unemployment increases the prevalence of acute morbidities by 3.9 percent. On the other hand, the fact that there is a positive relationship established between unemployment and mortality is found in Sweden, Europe, and Finland [81-83]. It is noteworthy to highlight that the mortality rate and the unemployment rate have a significant relationship, which may be between mortality rate and unemployment rate, but it can be expressed as a positive or negative correlation. On the contrary, Bonamore et al. [84] highlighted that the relationship between unemployment and mortality might be expressed in the form of U-shaped. The authors have demonstrated that though mortality negatively influences unemployment, the effect shifts to a positive when unemployment rises to 17 percent. The inconsistency of the relationship between these two variables highlights the necessity for continued research to determine the current association.

The second explanatory variable is the pension liabilities, which are computed from the expected present discounted value of retiree's pension annuities. The findings demonstrate a positive relationship between pension liabilities and mortality rates. A one percent increase in pension liabilities implies a 0.021 percent increase in the mortality rate. It implies that as the expected present discounted value received by retirees rises, the mortality rate rises as well. However, the association between pension liabilities and mortality demonstrates an insignificant relationship. But according to prior research by Ibrahim and the co-worker $[64,65]$, the mortality rate affects pension liabilities, but there is no evidence that pension liabilities influence the mortality rate. The empirical findings revealed that the relationship established is a one-way relationship with no direct influence due to other mechanisms being applied. Therefore, the government is encouraged to reform the existing pension scheme to address the issue of ballooning pension liabilities as recommended by Darmaraj and Narayanan [46].

The third explanatory variable is economic growth, which is extracted from gross domestic product data. The findings demonstrate that the gross domestic product variable has a significant negative relationship with the mortality rate. A one percent rise in GDP results in a 0.623 percent decrease in mortality rate. It reflects that there exists a short-run relationship between economic growth and mortality in Malaysia. Nevertheless, [25], who investigated the co-movement between mortality growth and economic fluctuations, found that a one percent increment in real GDP per capita results in a 0.27 percent drop in the mortality rate for the entire population. Furthermore, a similar association was revealed by Ruhm [19], who investigated the relationship between economic condition and health; a one percentage point increase in the state of unemployment causes a 0.5 to 0.6 percent reduction in total mortality annually. 
TABLE 1: Statistical descriptive of variables.

\begin{tabular}{|c|c|c|c|c|c|}
\hline & Variables & Mean & Minimum & Maximum & Standard deviation \\
\hline MR & $\begin{array}{c}\text { Overall } \\
\text { Across age groups } \\
\text { Time-series }\end{array}$ & -2.561887 & $\begin{array}{l}-3.137837 \\
-3.098683 \\
-2.601041 \\
\end{array}$ & $\begin{array}{l}-1.905553 \\
-1.923197 \\
-2.496378 \\
\end{array}$ & $\begin{array}{l}0.4556501 \\
0.5195171 \\
0.0220464 \\
\end{array}$ \\
\hline UR & $\begin{array}{c}\text { Overall } \\
\text { Across age groups } \\
\text { Time-series }\end{array}$ & 1.627995 & $\begin{array}{l}0.2897563 \\
0.8145354 \\
1.0277100 \\
\end{array}$ & $\begin{array}{l}.228231 \\
3.364145 \\
2.492063 \\
\end{array}$ & $\begin{array}{l}1.0932320 \\
1.1848510 \\
0.3431719 \\
\end{array}$ \\
\hline PL & $\begin{array}{c}\text { Overall } \\
\text { Across age groups } \\
\text { Time-series } \\
\end{array}$ & 6.490327 & $\begin{array}{l}3.7452210 \\
4.1883270 \\
5.7982960 \\
\end{array}$ & $\begin{array}{l}8.977172 \\
8.624142 \\
7.059179 \\
\end{array}$ & $\begin{array}{l}1.8352330 \\
2.0727080 \\
0.2665700 \\
\end{array}$ \\
\hline GDP & $\begin{array}{c}\text { Overall } \\
\text { Across age groups } \\
\text { Time-series } \\
\end{array}$ & 12.01080 & $\begin{array}{l}11.85300 \\
12.01080 \\
11.85300 \\
\end{array}$ & $\begin{array}{l}12.16060 \\
12.01080 \\
12.16060 \\
\end{array}$ & $\begin{array}{c}0.0980476 \\
0 \\
0.0980476 \\
\end{array}$ \\
\hline EDU & $\begin{array}{c}\text { Overall } \\
\text { Across age groups } \\
\text { Time-series }\end{array}$ & 5.08187 & $\begin{array}{l}3.958520 \\
5.081870 \\
3.958520 \\
\end{array}$ & $\begin{array}{l}5.974180 \\
5.081870 \\
5.974180 \\
\end{array}$ & $\begin{array}{c}0.5954689 \\
0 \\
0.5954689 \\
\end{array}$ \\
\hline HEXP & $\begin{array}{c}\text { Overall } \\
\text { Across age groups } \\
\text { Time-series }\end{array}$ & 10.61943 & $\begin{array}{l}10.44364 \\
10.61943 \\
10.44364\end{array}$ & $\begin{array}{l}10.78060 \\
10.61943 \\
10.78060\end{array}$ & $\begin{array}{c}0.1098562 \\
0 \\
0.1098562\end{array}$ \\
\hline
\end{tabular}

Table 2: Panel analysis regression model.

\begin{tabular}{|c|c|c|c|c|c|c|}
\hline Variables & Coefficient & Standard error & $t$ & $\operatorname{Pr}>|t|$ & \multicolumn{2}{|c|}{ 95\% confidence interval } \\
\hline UR & -0.0310763 & 0.0078479 & -3.96 & $(0.000)^{* * *}$ & -0.0470084 & -0.0151442 \\
\hline PL & 0.0208400 & 0.0130341 & 1.60 & $(0.119)$ & -0.0056205 & 0.0473006 \\
\hline GDP & -0.6232443 & 0.2949809 & -2.11 & $(0.042)^{* *}$ & -1.222087 & -0.0244013 \\
\hline EDU & -0.191435 & 0.0070369 & -2.72 & $(0.010)^{* * *}$ & -0.0334292 & -0.0048579 \\
\hline HEXP & 0.4194288 & 0.2520680 & 1.66 & $(0.105)$ & -0.0922964 & 0.931154 \\
\hline Constant & 0.4823 & 0.9360669 & 0.52 & $(0.610)$ & -1.418017 & 2.382617 \\
\hline
\end{tabular}

Note: $p$ values are shown in parentheses. Probability statistics are shown within parentheses; ${ }^{*},{ }^{* *}$, and ${ }^{* * *}$ indicate the significance of the explanatory variables at $10 \%, 5 \%$, and $1 \%$, respectively.

Moreover, Yang et al. [85] discovered a significant negative association between macroeconomic conditions and mortality in China. The relationship between these two, however, only works for all age groups of mortality but not for infant mortality rate [26]. The present study is consistent with the earlier evidence, indicating a significant negative relationship between GDP and mortality rate. The present study solely includes adults aged 25 to 64 years old as a sample without considering the infant mortality rate.

The next explanatory variable is the government expenditure on education. The empirical results suggest that a one percent increase in education expenditure results in a 0.191 percent decrease in mortality rate. The inverse relationship that has been established between these two variables shows a statistically significant relationship. The results are consistent with Ref. [86], who discovered an inverse relationship between education and older adult mortality in China. The mentioned authors also found that primary education has a greater effect on mortality in men than in women and that education has a greater influence on the young than the elderly. As a result, the government may enhance education expenditure in order to improve the post-COVID-19 mortality rate.

The last explanatory variable is the government healthcare expenditure. The empirical results suggest that a one percent increase in healthcare expenditure results in a 0.419 increase in the mortality rate. However, the relationship shows a statistically insignificant relationship. The results are consistent with a study carried out in Namibia by Shafuda and De [71], which found no cointegration observed between government spending on healthcare and adult mortality rates. The insignificant relationship between the two demonstrates that increasing the government healthcare expenditure does not ensure an increase in mortality rates. In order to reduce mortality, Abaluck et al. [87] proposed that offering effective insurance plans and redirecting consumers to such policies could improve beneficiary health and minimize mortality. In preparation for post-COVID-19, the government of Malaysia could implement the awareness of having a suitable insurance plan. By introducing a compulsory healthcare insurance plan for each household, the allocation of healthcare expenditure might be utilized to improve the insurance plan.

The findings should be interpreted in light of several limitations. First, the pension liabilities were only subject to the civil service pension scheme and did not include members of parliament, political secretaries, judges, and commission members to avoid bias. Second, there is data limitation for gross domestic product and government expenditure on education and healthcare. Since these variables limited data according to age group, the present study uses 
the same data for all age groups. This is unlikely to be a major issue because the panel regression model provides a robust model with no cross-sectional dependence, heteroscedasticity, and serial correlation problems.

\section{Conclusions}

The present study investigates the relationship between the unemployment rate, pension liabilities, economic growth, education expenditure, and healthcare expenditure on mortality rate in Malaysia. The fixed effects model is recommended to estimate the influence of unemployment rate, pension liabilities, economic growth, education expenditure, and healthcare expenditure on mortality rate. The fixed effects model was discovered to be a robust model with no cross-sectional dependence, heteroscedasticity, or serial correlation problems. The findings revealed that unemployment, economic growth, and education expenditure have statistically significant influences on the mortality rate. However, there is no evidence to support the idea that pension liabilities and healthcare expenditure have an influence on the mortality rate. Based on an R-squared value, the findings demonstrate that the explanatory variables could explain 84.69 percent of the mortality rate. The present study has demonstrated a statistically significant relationship between explanatory variables (unemployment rate, economic growth, and education expenditure) and the mortality rate. The results provide a novel contribution on how each explanatory variable could affect the mortality rate at the population level. The empirical findings suggest that all the significant variables have an inverse relationship with the mortality rate. Increasing the unemployment rate, economic growth, and education expenditure might lead to a decrement in the mortality. A decrement of the mortality rate reflects that the mortality rate improves, which is a good health indicator in Malaysia. In the wake of the COVID-19 higher mortality rate, the empirical results suggest raising the allocation for gross economic products and government education expenditure to improve the mortality rate. These two factors appear to have a greater influence on the mortality rate than the unemployment rate. Since the healthcare expenditure shows no influence on the mortality rate, the government is encouraged to create awareness about the importance of having a compulsory health insurance plan for each household. The government, insurance companies, and policymakers might come up with a special offer to help those who are unable to insure their families. Although the government provides a government hospital for individuals in need, health insurance could be another option to improve the mortality rate. In a nutshell, the government and other stakeholders can evaluate the remedy of changes in the mortality rate by estimating the mortality rate at the population level prior to the COVID-19 outbreak. Future studies in this topic are recommended to be conducted using the post-COVID-19 data to identify if there are any changes in the relationship established.

\section{Data Availability}

The data are collected from publicly available sources except for the ones that have been mentioned otherwise. The raw data supporting the conclusions of this manuscript will be made available by the authors without undue reservation.

\section{Conflicts of Interest}

The authors declare that there are no conflicts of interest related to this work.

\section{Authors' Contributions}

Robiaatul Adawiah Edrus assisted with data analysis, research framework, methodology, formal analysis, validation, literature review, and initial drafting. Zailan Siri was involved in conceptualization, validation, methodology, formal analysis, initial drafting, and supervision. Mohd Azmi Haron was involved in conceptualization, validation, methodology, formal analysis, resources, initial drafting, and supervision. Muhammad Aslam Mohd Safari took part in conceptualization, validation, methodology, formal analysis, provision of computer software, initial drafting, and supervision. Mohammed K.A. Kaabar participated in validation, methodology, resources, supervision, initial drafting, and editing. All authors read and approved the final version.

\section{Acknowledgments}

The authors would like to express their gratitude to the Department of Statistics, Malaysia (DOSM), the Rating Agency Malaysia (RAM), the post-pension division of the Public Service Department (JPA), and the Retirement Fund (Incorporated) for their cooperation in supplying the data needed for this study. In addition to that, the authors would like to express their appreciation to the Ministry of Higher Education (MOHE) Malaysia and Universiti Utara Malaysia (UUM) for the financial support and scholarship under Skim Latihan Akademik Bumiputera (SLAB).

\section{References}

[1] W. H. Hong, J. H. Yap, G. Selvachandran, P. H. Thong, and L. H. Son, "Forecasting mortality rates using hybrid LeeCarter model, artificial neural network and random forest," Complex \& Intelligent Systems, vol. 7, no. 1, pp. 163-189, 2021.

[2] C. C.-L. Tsai and E. S. Cheng, "Incorporating statistical clustering methods into mortality models to improve forecasting performances," Insurance: Mathematics and Economics, vol. 99, pp. 42-62, 2021.

[3] J. Cerda-Hernández and A. Sikov, "Lee-Carter method for forecasting mortality for Peruvian population," Selecciones Matemáticas, vol. 8, no. 1, pp. 52-65, 2021.

[4] S. M. Shaharudin, S. Ismail, N. A. Hassan, M. L. Tan, and N. A. F. Sulaiman, "Short-term forecasting of daily confirmed COVID-19 cases in Malaysia using RF-SSA model," Frontiers in Public Health, vol. 9, p. 625, 2021.

[5] X.-Q. Wang, G. Song, Z. Yang et al., "Association between ageing population, median age, life expectancy and mortality 
in coronavirus disease (COVID-19)," Aging, vol. 12, no. 24, pp. 24570-24578, 2020.

[6] M. A. Torres Acosta and B. D. Singer, "Pathogenesis of COVID-19-induced ARDS: implications for an ageing population," European Respiratory Journal, vol. 56, no. 3, Article ID 2002049, 2020.

[7] R. I. Ibrahim and N. Mohd Nordin, "Analysis of mortality improvement on the pension cost due to aging population," Matematika, vol. 36, no. 3, pp. 209-216, 2020.

[8] O. Šimpach and M. Pechrová, "Implications of the SARS-Cov2 pandemic for mortality forecasting: case study for the Czech republic and Spain," Engineering Proceedings, vol. 5, p. 58, 2021.

[9] S. Z. Jamaluddin, F. Yuen Wah, and M. Abu Taher, "COVID19: a preliminary assessment on the social security framework for an aged Malaysia," Commonwealth Law Bulletin, vol. 47, no. 1, pp. 55-71, 2021.

[10] C. F. Chung, S. Tan, J. B. Singau, K. H. Pazim, and K. Mansur, "The repercussions of COVID-19 Pandemic on the wellbeing of older people in Malaysia: a literature review," International Journal for Studies on Children, Women, The Elderly and Persons with Disabilities, vol. 11, pp. 17-23, 2020.

[11] C. Modi, V. Boehm, S. Ferraro, G. Stein, and U. Seljak, "Total COVID-19 mortality in Italy: excess mortality and age dependence through time-series analysis," 2020, https://www. medrxiv.org/content/10.1101/2020.04.15.20067074v1.

[12] S. Vandoros, "Excess mortality during the COVID-19 pandemic: early evidence from England and Wales," Social Science \& Medicine, vol. 258, Article ID 113101, 2020.

[13] K. Bogos, Z. Kiss, A. Kerpel Fronius et al., "Different trends in excess mortality in a central European country compared to main European regions in the year of the COVID-19 pandemic," Pathology and Oncology Research, vol. 27, pp. 1-9, 2020.

[14] L. Heligman and J. H. Pollard, "The age pattern of mortality," Journal of the Institute of Actuaries, vol. 107, no. 1, pp. 49-80, 1980.

[15] A. Kostaki, "A nine-parameter version of the HeligmanPollard formula," Mathematical Population Studies, vol. 3, no. 4, pp. 277-288, 1992.

[16] R. D. Lee and L. R. Carter, "Modeling and forecasting U.S. mortality," Journal of the American Statistical Association, vol. 87, no. 419, pp. 659-671, 1992.

[17] H. Booth and L. Tickle, "Mortality modelling and forecasting: a review of methods," Annals of Actuarial Science, vol. 3, no. 12, pp. 3-43, 2008.

[18] B. E. Hansen, "Challenges for econometric model selection," Economic Theory, vol. 21, pp. 60-68, 2005.

[19] C. J. Ruhm, “Are recessions good for your health?” Quarterly Journal of Economics, vol. 115, no. 2, pp. 617-650, 2000.

[20] C. J. Ruhm, "Good times make you sick," Journal of Health Economics, vol. 22, no. 4, pp. 637-658, 2003.

[21] E. Neumayer, "Recessions lower (some) mortality rates:," Social Science \& Medicine, vol. 58, no. 6, pp. 1037-1047, 2004.

[22] R. I. Ibrahim, N. M. Nordin, and M. Z. A. Chek, "Investigating the sensitivity effect of actuarial assumptions on pension liabilities in Malaysia," Baghdad Science Journal, vol. 18, pp. 830-835, 2021.

[23] N. H. Asmuni, S. N. S. S. M. Shahruddin, and N. Redzwan, "Value for money of retirement insurance plans in Malaysia with consideration of longevity factor," Pertanika Journal of Social Sciences \& Humanities, vol. 28, pp. 2265-2278, 2020.
[24] J. M. Poterba and A. Solomon, "Discount rates, mortality projections, and money's worth calculations for US individual annuities," 2021.

[25] M. Cavicchioli and B. Pistoresi, "Unfolding the relationship between mortality, economic fluctuations, and health in Italy," The European Journal of Health Economics, vol. 21, no. 3, pp. 351-362, 2020.

[26] H. Li, H. Feng, J. Wang, Z. Qian, and J. Gu, "Relationship among gross domestic product per capita, government health expenditure per capita and infant mortality rate in China," International Journal of Medical Sciences, vol. 28, 2017.

[27] J. M. Kirigia, D. Oluwole, G. M. Mwabu, D. Gatwiri, and L. H. Kainyu, "Effects of maternal mortality on gross domestic product (GDP) in the WHO African region," African Journal of Health Sciences, vol. 13, pp. 86-95, 2006.

[28] A. Eboh and S. Metiboba, "Econometric analysis of health care expedinture and access to Diphtheria Immunisation as predictor of under-five mortality rate in selected African countries," Humanus Discourse, vol. 1, pp. 7352-7363, 2021.

[29] S. Kousar, S. A. Batool, S. S. Batool, and M. Zafar, "Do government expenditures on education and health lead toward economic growth ? evidence from Pakistan," Journal of Research and Reflection in Educational Sciences, vol. 14, pp. 53-63, 2020.

[30] R. Okui and W. Wang, "Heterogeneous structural breaks in panel data models," Journal of Econometrics, vol. 220, no. 2, pp. 447-473, 2021.

[31] S. Taasim and A. Daud, "The effect of gender unemployment on economic growth: a panel data analysis," GATR Journal of Business and Economics Review, vol. 5, no. 3, pp. 94-103, 2020.

[32] M. Menhat, I. M. Mohd Zaideen, Y. Yusuf, N. H. M. Salleh, M. A. Zamri, and J. Jeevan, "The impact of COVID-19 pandemic: a review on maritime sectors in Malaysia," Ocean \& Coastal Management, vol. 209, Article ID 105638, 2021.

[33] S. Sundarasen, K. Chinna, K. Kamaludin et al., "Psychological impact of COVID-19 and lockdown among university students in Malaysia: implications and policy recommendations," International Journal of Environmental Research and Public Health, vol. 17, pp. 1-13, 2020.

[34] L. P. Foo, M. Y. Chin, K. L. Tan, and K. T. Phuah, "The impact of COVID-19 on tourism industry in Malaysia," Current Issues in Tourism, vol. 24, no. 19, pp. 2735-2739, 2020.

[35] M. W. Hasanat, F. A. S. Ashikul Hoque, P. Mashrekha Anwar, and A. B. A. Hamid, "Huam Hon Tat the impact of coronavirus on business continuity planning," Asian Journal of Multidisciplinary Studies, vol. 3, pp. 85-90, 2020.

[36] International Monetary Fund, 2021, https://www.imf.org/en/ Countries/MYS.

[37] C. F. Chung, K. H. Pazim, and K. Mansur, “Ageing population: policies and programmes for older people in Malaysia," Asian Journal of Education and Social Studies, vol. 2, pp. 92-96, 2020.

[38] Department of Statistics Malaysia, "Current population estimates, Malaysia, 2020," 2020, https://www.dosm.gov.my/v1/.

[39] Department of Statistics Malaysia, 2021: https://www.dosm. gov.my/v1/index.php?r=column/cthemeByCat\&cat=100\&bul_ id=TlpjcDZKcVlrNkpQVUFqOXBXeVRDZz09\&menu_ id=TE5CRUZCblh4ZTZMODZIbmk2aWRRQT09.

[40] C. F. Chung and K. Mansur, "A literature review on ageing population in selected Asian countries," Malaysian Journal of Business and Economics, vol. 5, pp. 79-92, 2018.

[41] The Fourth Malaysia Planpp. 1981-1985, 1985.

[42] N. A. Aziz, Y. Ahmad, and A. Zainuddin, "The evolution of government attention towards older person in Malaysia: a 
critical review of Malaysia 5 years plan," Administrative Sciences, vol. 14, pp. 1-14, 2017.

[43] A. Mahon, K. McNeill, and J. Heymann, "Pension programs around the world: new comparative global policy data," Journal of Comparative Policy Analysis: Research and Practice, vol. 17, no. 2, pp. 192-207, 2015.

[44] Post-Service Division and Public Service Department, Improvement of Pension Benefits, 2021, http://www.jpapencen. gov.my/english/improvement_pension.html.

[45] M. Asher and A. S. Bali, "Public pension programs in Southeast Asia: an assessment," Asian Economic Policy Review, vol. 10, no. 2, pp. 225-245, 2015.

[46] S. R. Darmaraj and S. Narayanan, "The long-term financial sustainability of the civil service pension scheme in Malaysia," Asian Economic Papers, vol. 18, no. 1, pp. 155-178, 2019.

[47] Mercer, "Melbourne mercer global pension Index 2019 report. Retrieved at march, 30 2021," 2019, https://www.mercer.com. au/our-thinking/mmgpi-2019.html.

[48] Office of Prime Minister Malaysia, "The number of civil servants remains the same despite the implementation of e-government," 2020, https://www.pmo.gov.my/ms/2020/08/ bilangan-penjawat-awam-kekal-meskipun-e-kerajaandilaksanakan-pm-muhyiddin/.

[49] M. Yunus Mawar and M. Adib Ismail, "Impact of population ageing on the Malaysian economy," in Proceedings of the 6th International Conference on Management and Muamalah 2019 (CoMM 2019), pp. 30-36, Granada, Spain, October 2019.

[50] T. L. Tai and N. M. Sapuan, "Retirement planning in Malaysia: issues and challenges to achieve sustainable lifestyle," Turkish Online Journal of Design Art and Communication, vol. 8, pp. 1222-1229, 2018.

[51] Z. Rozen-Bakher, "The raising of the normal retirement age (NRA) in the ageing era in the advanced countries: the dilemma between securing the stability of the pension system versus the risk of increasing unemployment," Policy Studies, vol. 41, no. 6, pp. 641-662, 2020.

[52] R. Jaafar, K. J. Daly, and A. V. Mishra, "Challenges facing Malaysia pension scheme in an era of ageing population," Finance Research Letters, vol. 30, pp. 334-340, 2019.

[53] The World Bank, 2021: https://data.worldbank.org.

[54] H. S. E. Gravelle, "Time series analysis of mortality and unemployment," Journal of Health Economics, vol. 3, no. 3, pp. 297-305, 1984.

[55] J. F. Forbes and A. McGregor, "Male unemployment and cause-specific mortality in postwar Scotland," International Journal of Health Services, vol. 17, no. 2, pp. 233-240, 1987.

[56] A. d'Errico, C. Piccinelli, G. Sebastiani et al., "Unemployment and mortality in a large Italian cohort," Journal of Public Health, vol. 43, pp. 361-369, 2021.

[57] R. L. Jin, C. P. Shah, and T. J. Svoboda, "The impact of unemployment on health: a review of the evidence," Journal of Public Health Policy, vol. 18, no. 3, pp. 275-301, 1997.

[58] J. A. T. Granados, "Recessions and mortality in Spain, 1980-1997," European Journal of Population/Revue européenne de Démographie, vol. 21, no. 4, pp. 393-422, 2005.

[59] P. T. Martikainen, "Unemployment and mortality among Finnish men, 1981-1985," BMJ, vol. 301, no. 6749, pp. 407-411, 1990.

[60] S. Sameem and K. Sylwester, "The business cycle and mortality: Urban versus rural counties," Social Science \& Medicine, vol. 175, pp. 28-35, 2017.

[61] C. Lee and K. Kim, "Changing relationship between unemployment and mortality in South Korea," Health Economics, vol. 26, no. 12, pp. 1630-1636, 2017.
[62] C. Uggla and S. Billingsley, "Unemployment, intragenerational social mobility and mortality in Finland: heterogeneity by age and economic context," Journal of Epidemiology \& Community Health, vol. 72, no. 11, pp. 1003-1008, 2018.

[63] R. I. Ibrahim and Z. Siri, "A study on longevity factor: the case of government pensioner in Malaysia," International Journal of Business and Social Science, vol. 16, pp. 147-161, 2015.

[64] R. I. Ibrahim and Z. Siri, "Study the impact on pension liabilities as the age of retirement increases," International Journal of Trade, Economics and Finance, vol. 4, pp. 247-251, 2013.

[65] R. I. Ibrahim, "Impact of increasing retirement age on longevity factor: an empirical study for government pensioners in Malaysia," Malaysian Journal of Economic Studies, vol. 46, pp. 29-35, 2012.

[66] U.-G. Gerdtham and M. Johannesson, "Business cycles and mortality: results from Swedish microdata," Social Science \& Medicine, vol. 60, no. 1, pp. 205-218, 2005.

[67] G. W. Comstock and J. A. Tonascia, "Education and mortality in Washington county, Maryland," Journal of Health and Social Behavior, vol. 18, no. 1, pp. 54-61, 1977.

[68] V. Albouy and L. Lequien, "Does compulsory education lower mortality?" Journal of Health Economics, vol. 28, no. 1, pp. 155-168, 2009.

[69] J. R. Warren, C. Muller, R. A. Hummer, E. Grodsky, and M. Humphries, "Which aspects of education matter for early adult mortality? evidence from the high school and beyond cohort," Socius: Sociological Research for a Dynamic World, vol. 6, Article ID 237802312091808, 2020.

[70] A. A. Leive and C. J. Ruhm, "Has mortality risen disproportionately for the least educated?" Journal of Health Economics, vol. 79, Article ID 102494, 2021.

[71] C. P. P. Shafuda and U. K. De, "Government expenditure on human capital and growth in Namibia: a time series analysis," Journal of Economic Structures, vol. 9, pp. 1-14, 2020.

[72] C. A. Gallet and H. Doucouliagos, "The impact of healthcare spending on health outcomes: a meta-regression analysis," Social Science \& Medicine, vol. 179, pp. 9-17, 2017.

[73] J. E. S. Søgaard, "Econometric critique of the economic change model of mortality," Social Science \& Medicine, vol. 34, pp. 947-957, 1992.

[74] E. L. Ionides, Z. Wang, and J. A. Tapia Granados, "Macroeconomic effects on mortality revealed by panel analysis with nonlinear trends," Annals of Applied Statistics, vol. 7, pp. 1362-1385, 2013.

[75] C. F. Tang, "Determinants of infant mortality rate in Malaysia: evidence from dynamic panel data study," Journal of Health Management, vol. 21, no. 4, pp. 443-450, 2019.

[76] S. Mitra, Q. Gao, W. Chen, and Y. Zhang, "Health, work, and income among middle-aged and older adults: a panel analysis for China," The Journal of the Economics of Ageing, vol. 17, Article ID 100255, 2020.

[77] A. Levin, C.-F. Lin, and C.-S. James Chu, "Unit root tests in panel data: asymptotic and finite-sample properties," Journal of Econometrics, vol. 108, no. 1, pp. 1-24, 2002.

[78] T. S. Breusch and A. R. Pagan, "The Lagrange multiplier test and its applications to model specification in econometrics," The Review of Economic Studies, vol. 47, no. 1, pp. 239-253, 1980.

[79] J. A. Hausman, "Specification tests in econometrics," Econometrica, vol. 46, no. 6, pp. 1251-1271, 1978.

[80] M. H. Pesaran, "A simple panel unit root test in the presence of cross-section dependence," Journal of Applied Econometrics, vol. 22, no. 2, pp. 265-312, 2007. 
[81] U.-G. Gerdtham and M. Johannesson, "A note on the effect of unemployment on mortality," Journal of Health Economics, vol. 22, no. 3, pp. 505-518, 2003.

[82] D. Vågerö and A. M. Garcy, "Does unemployment cause longterm mortality? Selection and causation after the 1992-1996 deep Swedish recession," The European Journal of Public Health, vol. 26, no. 5, pp. 778-783, 2016.

[83] L. Junna, H. Moustgaard, K. Huttunen, and P. Martikainen, "The association between unemployment and mortality: a cohort study of workplace downsizing and closure," American Journal of Epidemiology, vol. 189, no. 7, pp. 698-707, 2020.

[84] G. Bonamore, F. Carmignani, and E. Colombo, "Addressing the unemployment-mortality conundrum: non-linearity is the answer," Social Science \& Medicine, vol. 126, pp. 67-72, 2015.

[85] Z. Yang, R. Zheng, R. Zheng et al., "Comparison of cancer incidence and mortality in three GDP per capita levels in China, 2013," Chinese Journal of Cancer Research, vol. 29, no. 5, pp. 385-394, 2017.

[86] Y. Luo, Z. Zhang, and D. Gu, "Education and mortality among older adults in China," Social Science \& Medicine, vol. 127, pp. 134-142, 2015.

[87] J. Abaluck, M. Caceres Bravo, P. Hull, and A. Starc, "Mortality effects and choice across private health insurance plans," Quarterly Journal of Economics, vol. 136, no. 3, pp. 1557-1610, 2021. 